\title{
Porous architectures of boron-doped diamond for electroanalysis
}

\author{
Simona Baluchová ${ }^{1,2}$, Andrew Taylor', Silvia Sedláková2, Vincent Mortet², Ladislav Klimša², Jaromír \\ Kopeček ${ }^{2}$ and Karolina Schwarzová-Pecková ${ }^{1}$
${ }^{1}$ Charles University, Faculty of Science, Department of Analytical Chemistry, UNESCO Laboratory of Environmental Electrochemistry, Prague, Czech Republic
${ }^{2}$ FZU - Institute of Physics of the Czech Academy of Sciences, Prague, Czech Republic
E-mail: simona.baluchova@natur.cuni.cz

\section{Introduction}

Boron-doped diamond (BDD) is a well-established electrode material possessing unique properties [1], however, its performance can be significantly boosted by enlarging the effective surface area. For this reason, approaches focusing on fabrication of porous BDD ( $p$ BDD) electrode materials have been emerging and such electrodes have attracted lots of research interest due to their enhanced detection ability [2-6], manifested by increased sensitivity, improved selectivity, and lower detection limits, favouring them in sensors development area. Besides sensing, another promising field in which $p$ BDD materials can be particularly beneficial, owing to their remarkable biocompatibility, is neuroscience. These materials have proved suitable (i) substrates for neuron cultivation [7], (ii) sensors for detection of electroactive neurotransmitters [2-6], and (iii) devices for stimulation or recording of electric signals [8]. Therefore, development of a p-BDD-based device, enabling cultivation of neurons and recording their neurochemical and electrical signals, can be envisioned.

Despite the emerging interest in p-BDD materials, only a few studies dealing with the impact of selected 3D scaffolds and deposition conditions on their final properties can be traced in the literature, which is why this work aimed to elucidate factors having significant impact on the performance of $p-B D D$. Also, one type of $p-B D D$ developed within this study has already shown suitability for neuron cultivation [7], hence another goal of this work was to identify the best deposition parameters for fabrication of a p-BDD electrode fitting electrochemical sensing applications, and particularly targeting detection of electroactive neurotransmitters.

\section{Methods and Materials}

Within this work, twelve different types of $p-B D D$ electrode materials were successfully developed and prepared using a novel multi-step approach, whereby the bulk of the p-BDD electrode was made up of "thin" porous BDD layers; further details on the preparation can be found in $[2,4]$. The fabricated $p-B D D$ electrodes varied in (1) utilised deposition templates, (2) boron doping level [2], (3) growth time of the individual layers (i.e., porosity) [2], (4) number of deposited layers, and (5) content of nondiamond $\left(\mathrm{sp}^{2}\right)$ carbon [4]. To confirm the effect of porosity, conventional planar BDD films, grown on conductive silicon (cSi) wafers, were also studied for comparison. A summary of all prepared and tested BDD electrodes is provided in Tab. 1.

Subsequently, all developed p-BDD materials were thoroughly characterised, tested and compared using a range of techniques: (i) scanning electron microscopy (SEM) to observe the surface morphology and quality of deposited layers; (ii) Raman spectroscopy to assess the quality and diamond layer composition (estimation of boron and $\mathrm{sp}^{2}$ carbon content); (iii) cyclic voltammetry (CV) to evaluate electrochemical behaviour, particularly the width of the potential windows, double-layer capacitance values, effective surface area, electron transfer rate kinetics, proclivity to adsorption and fouling, response stability; (iv) square-wave voltammetry (SWV) to develop reliable method for detection of neurotransmitters and to assess analytical performance of $p-B D D$ electrodes in the terms of sensitivity and selectivity.

Tab. 1: An overview of all prepared and studied BDD electrodes.

\begin{tabular}{|c|c|c|c|c|}
\hline $\begin{array}{l}\text { Morpholo- } \\
\text { gy }\end{array}$ & Template & $\begin{array}{l}\text { B/C ratio } \\
\text { (ppm) }\end{array}$ & $\begin{array}{l}\text { Number } \\
\text { of layers }\end{array}$ & $\begin{array}{l}\text { Growth } \\
\text { time (h) }\end{array}$ \\
\hline planar & cSi wafer & 2000 & - & 5 \\
\hline planar & cSi wafer & $\begin{array}{l}500,1000,2000 \\
4000,8000\end{array}$ & - & 5 \\
\hline planar & cSi wafer & 4000 & - & 2.5 \\
\hline porous & $\begin{array}{l}\text { CNTs } \\
\text { CNTs + } \\
\mathrm{SiO}_{2} \mathrm{NFs} \\
\mathrm{SiO}_{2} \mathrm{NFs}\end{array}$ & 2000 & 4 & $\begin{array}{l}4 \times 2.5 \\
(10)\end{array}$ \\
\hline porous & $\mathrm{SiO}_{2} \mathrm{NFs}$ & $\begin{array}{l}500,1000,2000 \\
4000,8000\end{array}$ & 3 & $\begin{array}{l}3 \times 2.5 \\
(7.5)\end{array}$ \\
\hline porous & $\mathrm{SiO}_{2} \mathrm{NFs}$ & 4000 & $\begin{array}{l}2 \\
3 \\
5\end{array}$ & $\begin{array}{l}2 \times 5(10) \\
3 \times 5(15) \\
5 \times 5(25)\end{array}$ \\
\hline
\end{tabular}

\section{Results and Discussion}

Above-mentioned alterations in deposition conditions of p-BDD electrodes simultaneously represent the investigated parameters affecting their characteristics; each parameter was thoroughly examined and is discussed separately in the next paragraphs.

\section{Different templates used for deposition}

In the first step, three different types of $p-B D D$ materials were prepared using following porous scaffolds: (a) carbon 
nanotubes (CNTs; p-BDD-A), (b) a mixture of CNTs with silica $\left(\mathrm{SiO}_{2}\right)$ nanofibers (NFs) in a ratio of $1: 1$ (p-BDD-B), and (c) $\mathrm{SiO}_{2} \mathrm{NFs}$ only (p-BDD-C); all other deposition parameters were kept constant (see Tab. 1). The applicability of the p-BDD materials for sensing of neurotransmitters dopamine and serotonin and their precursors, tyrosine, L-DOPA and tryptophan, was examined in a $\mathrm{pH} 7.4$ phosphate buffer, which partially mimics the physiological conditions.

Scanning electron micrographs of all porous samples showed complete coverage of the structured template with a closed BDD layer. Nevertheless, the apparent porosity of the $p-B D D-A$ was reduced compared to other structured templates, which was, naturally, manifested in obtained electrochemical responses of studied analytes, resembling responses obtained on planar BDD electrode. Contrarily, on porous electrodes of $B$ and $C$ type, the characteristics related to the porous structure, thus to the increased electroactive area available for redox reactions could be easily recognized. Structuring the surface resulted in higher peak currents of all five tested compounds, which can lead to increased sensitivity. Also, oxidation of studied biomolecules occurred at lower potentials, which can positively affect selectivity. All in all, p-BDD-C manifested satisfactory porous character and the convenient signal to background ratio, therefore a $3 \mathrm{D}$ template based on $\mathrm{SiO}_{2}$ nanofibers was selected for further investigation and preparation of all other studied p-BDD electrodes.

\section{Boron-doping level}

Further, the influence of boron doping level $(\mathrm{B} / \mathrm{C}$ ratio in the gas phase: 500 ppm, 1000 ppm, 2000 ppm, 4000 ppm, and $8000 \mathrm{ppm}$ ) in fabricated p-BDD electrodes (3 layers; growth time $2.5 \mathrm{~h} /$ layer) was studied [2]. The results were compared with the set of conventional planar BDD electrodes deposited using the same $B / C$ ratios.

Concerning morphology, SEM images of porous samples confirmed that a 3D template consisting of $\mathrm{SiO}_{2}$ nanofibers was completely covered with BDD, except for B/C 8000 ppm, which showed regions of poor BDD coverage. As expected, for planar BDD films, a roughly $80 \%$ increase in the double layer capacitance, a $100 \mathrm{mV}$ narrower potential window and a $51 \mathrm{mV}$ negative shift of the peak potential of dopamine were observed when the boron doping level increased from $500 \mathrm{ppm}$ to $8000 \mathrm{ppm}$. Conversely, higher $\mathrm{sp}^{2}$ carbon content confirmed by Raman spectra affects the electrochemical performance of porous samples more significantly than the doping level. For the set of porous BDD electrodes, the double layer capacitance decreased by $\sim 95 \%$ with increasing boron content, peak-to-peak separation values of the inorganic redox markers were lower than $59 \mathrm{mV}$, suggesting their partial adsorption in the bulk of the material, and lower potentials for dopamine oxidation approaching values obtained for other $\mathrm{sp}^{2}$ carbon-based materials were recorded, but no dependency of potential values on boron concentration was revealed. Since maximal signal/background current ratio was obtained for the $4000 \mathrm{ppm} \mathrm{B/C}$ porous electrode, this doping level was chosen as optimal.

\section{Growth time of the individual layers}

After identifying suitable template $\left(\mathrm{SiO}_{2} \mathrm{NFs}\right)$ and boron doping level (B/C 4000 ppm), the growth time of individual porous layers was examined [2]. Two p-BDD electrodes were prepared, both with 3 layers, but grown for different times, either $2.5 \mathrm{~h} /$ layer (denoted as "thinner") or $5 \mathrm{~h} /$ layer (denoted as "thicker").

It is immediately evident from SEM images, shown in Fig. $1(\mathrm{~A})$, that porosity of "thicker" p-BDD sample was decreased, but on the other hand, the mechanical stability was considerably improved. Interestingly, using SWV with optimized parameters, enhanced selectivity for dopamine detection in a 100-fold excess of common interfering compounds such as uric acid, ascorbic acid (see Fig. 1(B)) and paracetamol was achieved [2], suggesting that selectivity of the p-BDD materials can be altered by adjusting their porosity. As a result, prolonged growth time of 5 hours of each layer was preferred for further examinations.
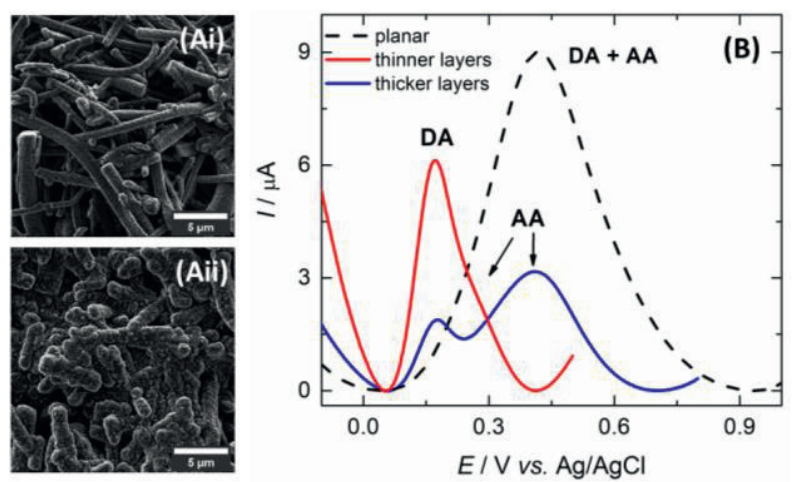

Fig. 1: (A) SEM images of (Ai) "thinner" (2.5 h/layer) and (Aii) "thicker" (5 h/layer) p-BDD electrodes. (B) SW voltammograms of a mixture of $10 \mu \mathrm{mol} \mathrm{L}^{-1}$ dopamine (DA) and $1000 \mu \mathrm{mol} \mathrm{L}-1$ ascorbic acid (AA) in a $\mathrm{pH} 7.4$ phosphate buffer recorded on $(--)$ planar BDD, $(-)$ "thinner" p-BDD and (-) "thicker" p-BDD electrodes.

Number of deposited porous layers and content of nondiamond $\left(s p^{2}\right)$ carbon

Finally, the last studied factor, whose impact on the characteristics and behaviour of p-BDD materials was clarified, was the number of deposited porous layers (2, 3 and 5) [4].

The boron doping level of $\sim 2 \times 10^{21}$ atoms $\mathrm{cm}^{-3}$ and increased content of non-diamond $\left(\mathrm{sp}^{2}\right)$ carbon in electrodes with more layers was evaluated by Raman spectroscopy. Moreover, CV experiments revealed reduced working potential windows (from $2.4 \mathrm{~V}$ to $2.2 \mathrm{~V}$ ), higher double-layer capacitance values (from $405 \mu \mathrm{F} \mathrm{cm}$-2 to $1060 \mu \mathrm{F} \mathrm{cm}{ }^{-2}$ ), enhanced rates of electron transfer kinetics and larger effective surface areas (from $5.04 \mathrm{~mm}^{2}$ to $7.72 \mathrm{~mm}^{2}$ ), when the number of porous layers increases.

Then, the behaviour of dopamine on all tested electrodes was studied by $\mathrm{CV}$ in a $\mathrm{pH} 7.4$ phosphate buffer. All recorded CVs depict a quasi-reversible redox system corresponding to the reaction of dopamine / dopamine-oquinone redox pair exchanging two electrons and two protons (see the mechanism in Fig. 2(A)). Apart from that, dopamine behaves dramatically different depending on the morphology of the BDD material, as it is immediately obvious from Fig. 2(B): On porous BDD, oxidation potential is less positive, peak-to-peak separation is significantly lower, and dopamine provides enhanced anodic peak currents and well-developed cathodic peaks, in comparison with planar BDD film. The observed electrochemical per- 
formance of dopamine on porous electrodes, especially with 3 and 5 layers (3L / 5L-p-BDD), can be associated with more electroactive sites available for redox reactions due to the surface structuring, as confirmed by higher values of effective surface area. However, these electroactive sites may be also related to the increased content of $\mathrm{sp}^{2}$ carbon, as indicated by Raman spectroscopy, which accelerate electron transfer kinetics and behave as adsorption sites for dopamine, and thus facilitate its redox reaction. Clearly, the dopamine redox reaction is extremely sensitive to the surface chemistry of $\mathrm{sp}^{2}$ and $\mathrm{sp}^{3}$ carbon due to the structuring of the BDD surface.
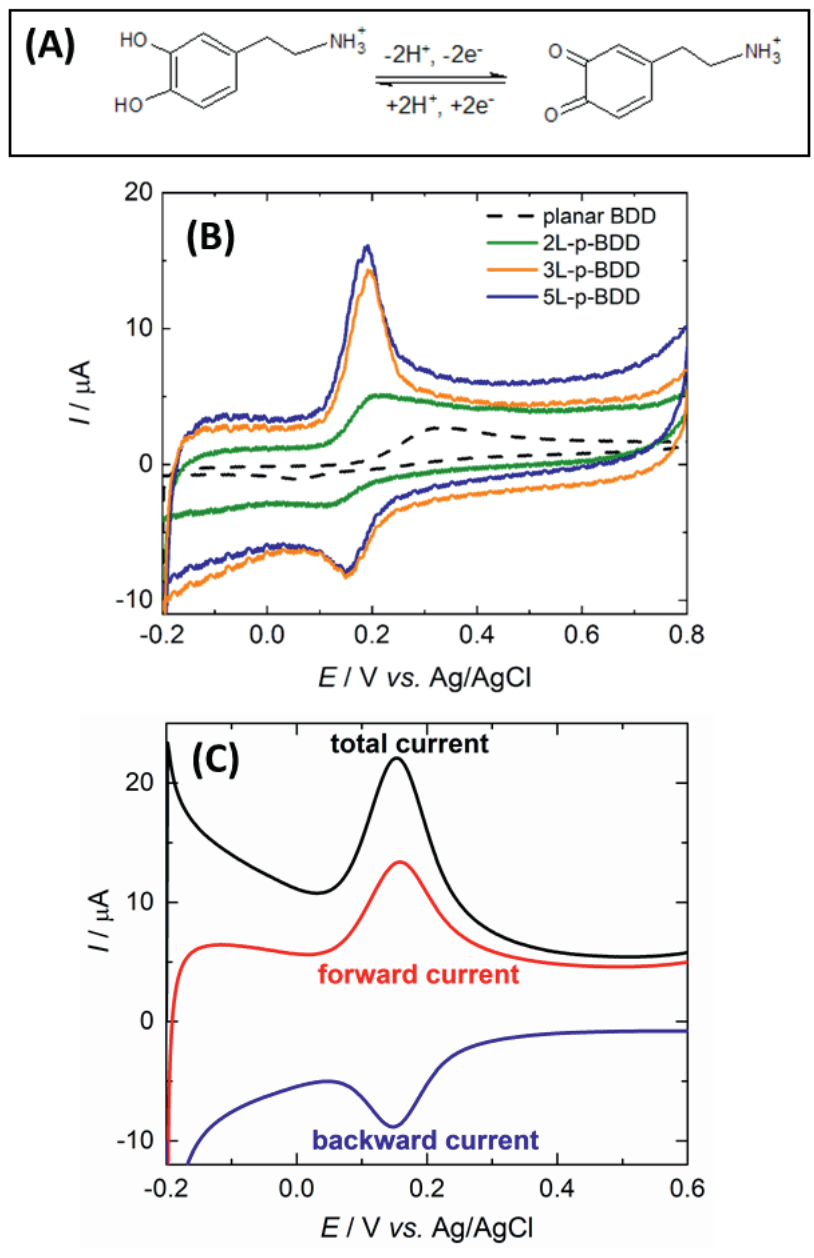

Fig. 2: (A) First reversible step in oxidation mechanism of dopamine. (B) CVs of $1 \mathrm{mmol} \mathrm{L}^{-1}$ dopamine in a $\mathrm{pH} 7.4$ phosphate buffer $\left(0.1 \mathrm{~mol} \mathrm{~L}^{-1}\right)$ recorded on planar and porous BDD electrodes. (D) SW voltammogram of

$1 \mathrm{mmol} \mathrm{L}{ }^{-1}$ dopamine recorded on the $3 \mathrm{~L}-\mathrm{p}-\mathrm{BDD}$ electrode, showing the individual forward and backward components of the total current.

To take advantage of the quasi-reversible behaviour of dopamine on porous electrodes, the SWV technique was selected to develop a reliable method for dopamine determination. Optimization of operational parameters resulted in symmetric recordings of both forward and backward currents, which is also reflected in the obtained total current responses (see Fig. 2(C) for the 3L-p-BDD electrode). Another beneficial feature of SWV is the fast scan inhibiting formation of a passivating layer, therefore satisfactory repeatability was confirmed on all p-BDD elec- trodes without applying any surface activation procedure between consecutive scans.

Next, concentration dependences of dopamine were recorded up to a concentration level of $30 \mu \mathrm{mol} \mathrm{L^{-1 }}$, covering and even exceeding dopamine levels in neural tissues (typically in $\mu \mathrm{mol} \mathrm{L^{-1 }}$ units). Importantly, a significant boost in analytical performance was recognized with increasing number of layers using SWV: the highest sensitivity and the lowest detection limit of $0.20 \mu \mathrm{mol} \mathrm{L}^{-1}$ was obtained on a $5 \mathrm{~L}-\mathrm{p}-\mathrm{BDD}$ electrode.

\section{Designed $p-B D D$ electrode}

For electrochemical sensing applications, particularly targeting neurotransmitter dopamine, a $\mathrm{SiO}_{2}$ nanofibersbased $\mathrm{p}$-BDD electrode with five deposited porous layers (while each layer grew for 5 hours), boron doping level of $4000 \mathrm{ppm}$ and higher $\mathrm{sp}^{2}$ content, was identified as the most suitable.

Subsequently, further experiments were performed with the designed $p$-BDD electrode. Briefly, possibility of dopamine detection in more complex bio-mimicking media was verified $[3,4]$. The first studied pseudo-physiological environment was a common tissue culture medium, HEPES buffered saline, where HEPES (see Fig. 3(A) for the structure) is a buffering agent. This compound was confirmed electroactive within the scope of this work [3]. Nevertheless, no negative impact on dopamine signals was noticed. Concentration dependence of dopamine was recorded on the designed $5 \mathrm{~L}-\mathrm{p}-\mathrm{BDD}$ electrode in HEPES buffered saline using the developed SWV method and analytical parameters (sensitivity, linear range, LOD) comparable to those reported for a simple phosphate buffer were achieved [3]. Also, HEPES is a main buffering component of an even more complex environment, Neurobasal medium, which is widely utilised in neuron cultivation experiments. Importantly, eight out of its 37 components were identified electroactive, including HEPES. However, no signals, which could be associated with these compounds, were detected in CV or SWV recorded within the investigated potential range from $-0.2 \mathrm{~V}$ to $+0.8 \mathrm{~V}$ on the $5 \mathrm{~L}-\mathrm{p}$ BDD electrode [4]. In the next step, the applicability of the developed $5 \mathrm{~L}-B D D_{\text {porous }}$ electrode and SWV protocol was verified for dopamine determination in the spiked Neurobasal medium using the standard addition method. The found dopamine concentration $\left(10.1 \pm 0.2 \mu \mathrm{mol} \mathrm{L} \mathrm{L}^{-1}\right)$ corresponded very well to the added one $\left(10.0 \mu \mathrm{mol} \mathrm{L} \mathrm{L}^{-1}\right)$. This confirmed that dopamine can be accurately determined on the 5L-p-BDD electrode even in such complex biomimicking solution and the proposed SWV method was not severely impacted by any matrix effects [4].<smiles>O=S(=O)(O)CCN1CCN(CCO)CC1</smiles>

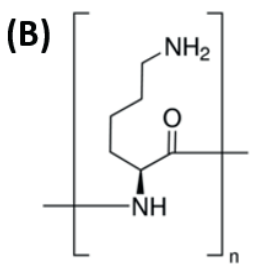

Fig. 3: Chemical structure of (A) HEPES compound and (B) poly-L-lysine.

Moreover, to achieve successful neuron cultivation, besides using Neurobasal-based media, very often a surface treatment is required to promote adhesion and effective 
attachment of neural cells to the growth substrate. Such treatment is usually performed by coating material with selected cationic polymer, most widely used is poly-Llysine (PLL) [7], depicted in Fig. 3(B). Therefore, the modification of designed $p-B D D$ electrode with PLL was performed according to standard procedure used in neuron cultivation experiments $\left(10 \mu \mathrm{g} \mathrm{mL}^{-1} \mathrm{PLL}\right.$ dissolved in a $\mathrm{pH}$ 8.4 borate buffer $\left(0.15 \mathrm{~mol} \mathrm{~L}^{-1}\right)$ was applied on the electrode surface and left at room temperature for $1 \mathrm{~h}$ ) [7] and investigated from electrochemical point of view [4]. The application of PLL coating on porous electrode surface resulted in a decrease in dopamine peak currents by $17 \%$, whilst the peak potentials remained constant. Further, the PLL layer formed on the p-BDD was not stable enough and removal of PLL was observed through increased dopamine currents even when the surface was simply rinsed with water [4]. These findings should be taken into consideration when preparing electrode-neural interfaces, particularly when intended applications aim to also cover electrochemical sensing of neurotransmitters.

\section{Conclusion}

To summarize, changing morphology is a powerful approach of how to significantly enhance the sensing ability of the BDD electrodes. Regarding newly fabricated p-BDD electrode materials, every parameter investigated in this study was manifested to have a significant impact on their morphological features and electrochemical performance. The most convenient deposition conditions were identified and selected to produce a $\mathrm{p}-\mathrm{BDD}$ electrode targeting sensitive and selective detection of dopamine. However, deeper understanding of factors influencing the final properties can possibly lead to a rational design of new and highly perspective $p$-BDD electrode materials, whose properties can be tuned for the specific purposes. As a consequence, expansion of in-vitro and in-vivo applications of $p-B D D$-based materials in electroanalysis, sensors development and neuroscience can be envisioned.

\section{Literature}

[1] BALUCHOVÁ, S. ; DAŇHEL, A. ; DEJMKOVÁ, H. ; OSTATNÁ, V. ; FOJTA, M. ; SCHWARZOVÁPECKOVÁ, K.: Recent progress in the applications of boron doped diamond electrodes in electroanalysis of organic compounds and biomolecules - A review. In: Anal Chim Acta 1077 (2019), S. 30-66

[2] BALUCHOVÁ, S. ; TAYLOR, A. ; MORTET, V. ; SEDLÁKOVÁ, S. ; KLIMŠA, L. ; KOPEČEK, J. ; HÁK, O. ; SCHWARZOVÁ-PECKOVÁ, K: Porous boron doped diamond for dopamine sensing: Effect of boron doping level on morphology and electrochemical performance. In: Electrochim Acta 327 (2019), 135025

[3] BRYCHT, M. ; BALUCHOVÁ, S. ; TAYLOR, A. ; MORTET, V. ; SEDLÁKOVÁ, S. ; KLIMŠA, L. ; KOPEČEK, J. ; SCHWARZOVÁ-PECKOVÁ, K.: Comparison of electrochemical performance of various boron-doped diamond electrodes: Dopamine sensing in biomimicking media used for cell cultivation. In: Bioelectrochemistry 137 (2021), 107646

[4] BALUCHOVÁ, S. ; BRYCHT, M. ; TAYLOR, A. ; MORTET, V. ; KRŮŠEK, J. ; DITTERT, I. ; SEDLÁKOVÁ, S. ; KLIMŠA, L. ; KOPEČEK, J. ; SCHWARZOVÁPECKOVÁ, K.: Enhancing electroanalytical performance of porous boron-doped diamond electrodes by increasing thickness for dopamine detection. In: Anal Chim Acta 1182 (2021), 338949

[5] LI, Y.R. ; LI, H.J. ; LI, M.J. ; LI, C.P. ; SUN, D.Z. ; YANG, B.H.: Porous boron-doped diamond electrode for detection of dopamine and pyridoxine in human serum. In: Electrochim Acta 258 (2017), S. 744-753

[6] MAY, P.W. ; CLEGG, M. ; SILVA, T.A. ; ZANIN, H. ; FATUBELLO-FILHO, O. ; CELORRIO, V. ; FERMIN, D.H. ; WELCH, C.C. ; HAZELL, G. ; FISHER, L. ; NOBBS, A. ; SU, B.: Diamond-coated 'black silicon' as a promising material for high-surface-area electrochemical electrodes and antibacterial surfaces. In: J Mat Chem B 4 (2016) S. 5737-5746

[7] KRŮŠEK, J. ; DITTERT, I. ; SMEJKALOVÁ, T. ; KOŘÍNEK, M. ; GOTTFRIEDOVÁ, K. ; FREISLEBENOVÁ, H. ; NEUHOFEROVÁ, E. ; KLIMŠA, L. ; SEDLÁKOVÁ, S. ; TAYLOR, A. ; MORTET, V. ; PETRÁK, V.: Molecular Functionalization of Planar Nanocrystalline and Porous Nanostructured Diamond to Form an Interface with Newborn and Adult Neurons. In: Phys Status Solidi B-Basic Solid State Phys 256 (2019), 1800424

[8] MEIJS, S. ; MCDONALD, M. ; SORENSEN, S. ; RECHENDORFF, K. ; FEKETE, L. ; KLIMŠA, L. ; PETRAK, V. ; RIJKHOFF, N. ; TAYLOR, A. ; NESLADEK, M. ; PENNISI, C.P.: Diamond/porous titanium nitride electrodes with superior electrochemical performance for neural interfacing. In: Front Bioeng Biotechnol 6 (2018) 171

\section{Acknowledgement}

Funding provided by the Specific University Research [SVV 260560], the Grant Agency of Charles University [project 390119] and the Czech Science Foundation [project 20-03187S] is gratefully acknowledged. 